\title{
AVALIAÇÃO DE ALTERNATIVAS DE PRÉ-OXIDAÇÃO EM ESTAÇÃO DE TRATAMENTO DE ÁGUA
}

\author{
Tamy N. T. P. da Silva (EM), Andressa A. Modesto (EM), Júlia C. S. Baía (EM), Eric A. M. Rodrigues \\ (IC), Maria A. Carvalho de Medeiros (PQ).
}

\section{Resumo}

Dentre as tecnologias de desinfecção, o cloro ainda é o agente oxidante mais utilizado. A formação de subprodutos de desinfecção (SPDs) tem sido relatada nos estudos sobre a aplicação de cloro em água superficial. Os oxidantes alternativos ao cloro têm sido um caminho para a minimização desses SPDs nas Estações de Tratamento de Água (ETAs). Desta forma, o objetivo deste trabalho foi analisar por meio de ensaios laboratoriais, utilizando o Jar Test, o processo de pré-oxidação, aplicando-se dióxido de cloro, o peróxido de hidrogênio e o hipoclorito de sódio nas águas brutas dos mananciais: rio Jaguari e ribeirão Pinhal. Analisando-se os trihalometanos (THMs) por Cromatografia Gasosa utilizando extração e préconcentração Purge and Trap. A utilização do $\mathrm{H}_{2} \mathrm{O}_{2}$ na pré-oxidação apresentou os menores valores de THMs.

Palavras Chave: Dióxido de Cloro, Peróxido de Hidrogênio, Trihalometanos.

\section{Introdução}

A principal medida na prevenção de doenças de veiculação hídrica tem sido a operação do processo de desinfecção nas ETAs. No Brasil, o cloro é comumente utilizado para este fim, sendo que estudo recente [1] relatou que são gerados subprodutos de desinfecção (SPDs), vários estudos têm relatado que estes são potencialmente cancerígenos [2], sendo fundamental minimizá-los [1, 2].

\section{Resultados e Discussão}

Após a realização das 4 etapas da metodologia: Caracterização da água bruta, Ensaios preliminares para a avaliação dos préoxidantes, Tratamento da água e Análise dos SPDs, nota-se uma diminuição significativa dos valores de THMs totais, mostrado na Tabela 1.

Tabela 1. Subprodutos da pré-oxidação com $\mathrm{H}_{2} \mathrm{O}_{2}, \mathrm{ClO}_{2}$ e $\mathrm{NaClO}$ para cada manancial.

\begin{tabular}{|c|c|c|c|c|c|c|}
\hline \multirow{3}{*}{ Subprodutos $(\mu / L)$} & \multicolumn{6}{|c|}{ Pré-oxidante } \\
\hline & \multirow{2}{*}{\multicolumn{2}{|c|}{$\begin{array}{c}\mathrm{H}_{2} \mathrm{O}_{2} \\
\text { Pinhal Jaguari }\end{array}$}} & \multicolumn{2}{|c|}{$\mathrm{ClO}_{2}$} & \multicolumn{2}{|c|}{$\mathrm{NaClO}$} \\
\hline & & & Pinhal & Jaguari & Pinhal & Jaguari \\
\hline Clorofórmio & 9,199 & 6,870 & 34,777 & 46,772 & 92,838 & 10 \\
\hline Brom & 0,148 & 0,007 & 3,928 & 20,604 & 25,277 & 38 \\
\hline Clor & 0 & 0,0 & 0,749 & 2,149 & 0 & 2 \\
\hline Brom & 6 & 0,000 & 1,028 & 0,824 & 0,694 & \\
\hline Total THM & 9,690 & 6,943 & 40,482 & 70,348 & 119,406 & 142,735 \\
\hline
\end{tabular}

Os dados de THMs totais e dos parâmetros: turbidez, cor e absorbância em $\lambda=254 \mathrm{~nm}$ (medida indireta da matéria orgânica) são observados na Tabela 2.
Tabela 2. Resultados das análises físicoquímicas e de THMs utilizando os pré-oxidantes

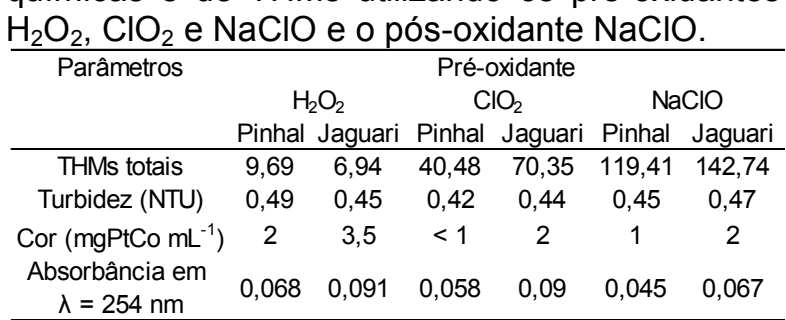

Nota-se que houve uma grande diferença na concentração de THMs totais formados para os diferentes pré-oxidantes, enquanto não há uma grande variação dos parâmetros físico-químicos. Os pré-oxidantes alternativos ao cloro demonstraram eficiência na redução da concentração de THMs totais.

\section{Conclusões}

Conclui-se que para o parâmetro THMs totais, somente os pré-oxidantes alternativos ao cloro: $\mathrm{H}_{2} \mathrm{O}_{2}$ e $\mathrm{ClO}_{2}$ atenderam ao valor máximo permitido (VMP) da Portaria 2.914/2011 (THMs = $100 \mu \mathrm{g} \mathrm{L}^{-1}$ ). A utilização do $\mathrm{H}_{2} \mathrm{O}_{2}$ na pré-oxidação apresentou os menores valores de THMs.

\section{Agradecimentos}

Ao programa CNPq/PIBIC EM pelo financiamento do projeto de pesquisa, à UNICAMP pela concessão das bolsas de Iniciação Científica.

[1] RODRIGUES, E. A. M. Avaliação de alternativas de préoxidação com dióxido de cloro e peróxido de hidrogênio em Estação de Tratamento de Água com dois mananciais de captação: ribeirão Pinhal e rio Jaguari. Trabalho de Conclusão de Curso. Orientadora: Profa.Dra. Maria A. Carvalho de Medeiros. Faculdade de Tecnologia. Universidade Estadual de Campinas, 2015.

[2] DI BERNARDO, L.; DANTAS, A. D. B. Métodos e técnicas de tratamento de água. São Carlos, SP: RiMa Editora, 2005. v. 1. 